\title{
Monitoring dan Evaluasi Sistem Informasi Akademik Universitas Halmahera Menggunakan Cobit 4.1
}

\author{
Abraham Madubun ${ }^{1}$, Augie David Manuputty² \\ 1,2Information System, Faculty of Technology Information, Satya Wacana Christian University, \\ Indonesia. \\ Email: 1682015038@student.uksw.edu, 2augie.manuputty@uksw.edu
}

\begin{abstract}
This article aims to evaluate the performance of the Academic Information System using the COBIT 4.1 framework at the University of Halmahera. Evaluation of the performance of the application of Information Technology at Halmahera University is needed to identify various obstacles based on existing conditions. Furthermore, the existing situation is assessed and compared with the expected value. Thus, it can be recommended for the optimization of Information Technology in educational institutions. The evaluation results show that the University of Halmahera has implemented a monitor and evaluate framework at the Defined Process level. Based on interviews and questionnaires results, it shows that the maturity level has an average of 3.8 with an expected level of level 4 , namely managed and measurable, and has a GAP value of 0.24 . Through the calculation of the maturity level results, it shows that the subdomain with the highest value is in ME4, which is 3.92, which is at the Defined Process level, and for the subdomain with the lowest value is ME1 with a value of 3.59, which is at the Defined Process level.
\end{abstract}

Keywords: Monitoring and Evaluation; Information System, Halmahera University, Cobit 4.1

\section{PENDAHULUAN}

Control Objective for Information and Related Technology (COBIT) merupakan kerangka yang dapat digunakan untuk melakukan pengawasan, evaluasi, hingga penilaian terhadap penggunaan sistem informasi di berbagai lembaga [1]. Adopsi teknologi informasi untuk kepentingan komunikasi di berbagai instansi perlu dievaluasi untuk mengukur performa atau kinerja dari sistem informasi [2]. Dalam konteks lembaga pendidikan, implementasi Sistem Informasi Akademik (SISFORMIK) dapat dievaluasi untuk mengoptimalkan fungsi sistem dalam mendukung kinerja lembaga [3]. [4] Menunjukkan bahwa hasil evaluasi 
menggunakan kerangka COBIT dapat dikolaborasikan dengan IT Balanced Scorecard untuk perbaikan penerapan sistem yang lebih optimal. Hal ini menunjukkan bahwa COBIT menjadi salah satu kerangka yang dapat digunakan untuk mengawasi dan mengevaluasi kinerja sistem di lembaga pendidikan.

Kerangka COBIT mengalami perkembangan seiring dengan perkembangan teknologi dan kebutuhan perusahaan. Hal tersebut berimplikasi pada penambahan indikator pada kerangka COBIT. Terdapat perbedaan fasilitas dalam domain Cobit 4.0 yang diterbitkan tahun 2005 dengan COBIT 4.1 yang diterbitkan tahun 2007 yakni pada tata kelola (governance) dan kepatuhan (compliance) [5]. COBIT 4.0 atau 4.1 memiliki prinsip penyedia informasi bagi organisasi dengan cara mengelola dan mengendalikan sumberdaya Teknologi Informasi (Aplikasi, Informasi, Infrastruktur dan Orang) [6]. Dalam upaya mengoptimalkan kebijakan, perencanaan dan prosedur, serta struktur organisasi, maka COBIT memberikan kerangka tatakelola TI melalui Detailed Control Objective (DCO) yang terdiri dari empat domain yakni Planning and Organization (PO), Acquisition and Implementation (Al), Delivery and Support (DS), dan Monitoring and Evaluate (ME).

Beberapa penelitian tentang COBIT menunjukkan adanya perbedaan yang signifikan antara COBIT 4.0/4.1 dengan COBIT 5. COBIT 5 diterbitkan pada tahun 2012 untuk mengurangi resiko dan meningkatkan kepercayaan terkait dengan pemanfaatan TI yang dihasilkan [7]. COBIT 5 memiliki dua fokus yakni tatakelola (governance) dan manajemen (management) yang dikenal dengan isitlah Evaluating, Direction, Monitoring (EDM) untuk proses Plans, Builds, Runs, Monitors (PBRM) [8]. COBIT 5 memiliki lima prinsip yakni : mempertemukan kebutuhan stakeholder; melingkupi kegiatan organisasi hingga akhir; menerapkan kerangka terpadu; menerapkan pendekatan yang holistic; serta pemisahan yang jelas antara tatakelola dan manajemen [9]. Lebih jauh, COBIT 5 juga mengaktifkan beberapa fitur sebagai berikut : prinsip-prinsip, kebijakan-kebijakan, dan kerangka kerja; proses-proses; struktur organisasi; budaya, etika dan perilaku; informasi; layanan, infrastruktur dan aplikasi; orang, keterampilan, dan kompetensi [10].

Dalam konteks penelitian ini, kerangka COBIT yang digunakan ialah COBIT 4.1 dengan fokus utama pada domain Monitoring and Evaluate (ME) di lembaga Pendidikan Tinggi. Beberapa studi serupa yang menggunakan kerangka COBIT 4.0/4.1 untuk mengevaluasi sistem informasi akademik pada domain ME, menunjukkan adanya gap antara kondisi eksisting dengan ideal yang kontekstual. [11] menunjukkan bahwa tingkat kematangan implementasi e-learning di Universitas Bumi Gora (UBG) pada domain ME berada di level 3 namun terdapat 


\section{Journal of Information Technology Ampera \\ Vol. 2, No. 2, August 2021 e-ISSN: 2774-2121}

https://journal-computing.org/index.php/journal-ita/index

gap dengan kondisi eksisting sebesar 1.17. Disisi lain, [12] menunjukkan bahwa tingkat kematangan di Politeknik Kesehatan Kemenkes Surabaya pada domain ME berada di level 2. Hal ini menunjukkan bahwa masing-masing lembaga pendidikan memiliki hambatan dan tantangan dalam mengoptimalkan sistem informasi akademik yang beragam [13], [14]. Dengan demikian, penelitian fokus memonitoring dan mengevaluasi sistem informasi akademik menggunakan kerangka kerja COBIT 4.1 pada domain ME berdasarkan konteks Universitas Halmahera.

Universitas Halmahera merupakan salah satu Perguruan Tinggi dengan kode 121015 yang aktif serta memiliki nilai akreditasi Baik Sekali. Sejak berdiri tanggal 22 September tahun 2008 sebagaimana SK Perguruan Tinggi Nomor 200D02008, Universitas Halmahera yang beroperasional di Kabupaten Halmahera Utara, telah memanfaatkan teknologi informasi untuk mengoptimalkan sistem akademik. Secara spesifik, proses bisnis dalam sistem informasi akademik di Universitas Halmahera mengakomodir pelbagai kepentingan administrasi perkuliahan untuk dosen dan mahasiswa secara terintegrasi. Urgensi penelitian ini ialah untuk mengevaluasi kinerja sistem informasi akademik Universitas Halmahera yang mengakomodir pelbagai kepentingan dosen dan mahasiswa dari 15 program studi berbeda yakni : Agroteknologi; Akuntansi; Fisika; IImu Administrasi Negara; IImu Hukum; IImu Pemerintahan; IImu Teologi; Kehutanan; Manajemen Sumberdaya Perairan; Matematika; Pendidikan Agama Kristen; Pendidikan Guru Sekolah Dasar; Teologi; Pendidikan Agama Kristen; Manajemen. Mempertimbangkan hal tersebut, domain Monitoring and Evaluate (ME) yang digunakan dalam penelitian ini terbagi menjadi empat bagian yakni Monitor and Evaluate IT Performance (ME1); Monitor and Evaluate Internal Control (ME2); Obtain Independent Assurance (ME3); dan Provide IT Governance (ME4).

\section{METODE}

Metode penelitian yang digunakan ialah metode campuran dengan pendekatan studi kasus di Universitas Halmahera. Teknik pengambilan data yang digunakan ialah wawancara mendalam, observasi, studi dokumen dan kuesioner. Sedangkan, teknik pengolahan data menggunakan trianggulasi, untuk memperoleh informasi yang valid dan kredibel. Adapun, tahapan penelitian ini terbagi menjadi empat tahap sebagaimana Gambar 1 berikut. 


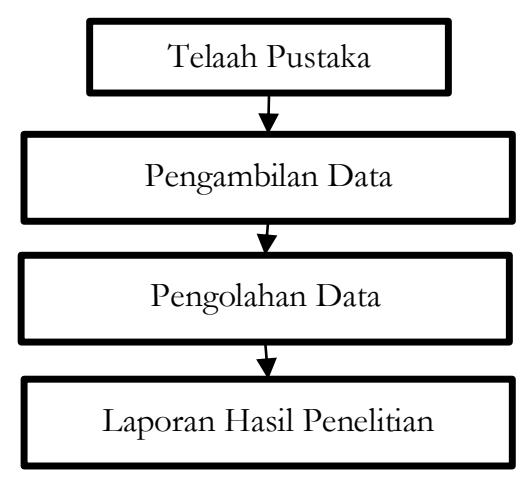

Gambar 1. Tahapan penelitian

Gambar 1 merupakan tahapan penelitian yang dapat dideskripsikan sebagai berikut : tahap pertama, telaah pustaka diperlukan untuk mengkaji secara mendalam kerangka kerja COBIT 4.0/4.1 dan COBIT 5. Hasil penelitian terdahulu yang menggunakan kerangka kerja COBIT diklasifikasikan berdasarkan karakteristik lembaga, domain, dan tingkat kematangan. Berdasarkan hasil telaah pustaka, dapat diketahui bahwa lembaga pendidikan yang mengadopsi sistem informasi akademik perlu dievaluasi menggunakan kerangka kerja COBIT 4.1 pada domain Monitoring dan Evaluate (ME) untuk mengukur tingkat kematangan, melalui identifikasi gap antara kondisi eksisting dengan kondisi ideal yang diharapkan oleh lembaga yang diteliti (Universitas Halmahera); Tahap kedua, proses pengambilan data penelitian ini menggunakan wawancara mendalam untuk memperoleh gambaran secara mendalam tentang hambatan dan tantangan dari perspektif kelembagaan khususnya direktur akademik, kepala bidang ICT dan tenaga kependidikan sebagai pengguna sistem di Universitas Halmahera. Adapun, pertanyaan penelitian dirumuskan berdasarkan konsep Responsible, Accountable, Consulted, Informed (RACl). RACl merupakan matriks untuk seluruh aktivitas atau otorisasi keputusan yang harus diambil dalam suatu organisasi yang dikaitkan dengan seluruh pihak.

Secara spesifik, Responsible menekankan pada konfrimasi aktivitas yang berhubungan dengan sistem informasi akademik telah terimplementasi, sehingga perlu dilakukan wawancara kepada orang yang melalukan suatu kegiatan atau pekerjaan terkait sistem informasi akademik. Selanjutnya, Accountable menekankan pada otoritas atau kewenangan menerima dan menyetujui pelaksanaan program yang berhubungan dengan sistem informasi akademik, sehingga perlu dilakukan wawancara terhadap orang yang bertanggungjawab atau memiliki otoritas dalam memutuskan suatu perkara. Disisi lain, Consulted, 


\section{Journal of Information Technology Ampera \\ Vol. 2, No. 2, August 2021 e-ISSN: 2774-2121}

https://journal-computing.org/index.php/journal-ita/index

menekankan pada interaksi untuk memberikan pendapat yang dibutuhkan dalam mengimplementasikan sistem informasi akademik, sehingga perlu dilakukan wawancara terhadap orang yang memberikan umpan balik atau saran. Adapun, Informed, yakni pihak-pihak yang menggunakan sistem infomrasi akademik di Universitas Halmahera sehingga perlu dilakukan wawancara terhadap orang yang mengetahui hasil dari suatu keputusan terkait SISFORMIK Uniera.

Selain wawancara mendalam, observasi juga dilakukan dengan mengamati ruangan administratsi, laboratorium ITC, hingga installasi jaringan kampus sebagai infrastruktur fisik pendukung sistem informasi akademik di Universitas Halmahera. Studi dokumen juga dilakukan dengan memastikan ketersediaan perangkat teknologi informasi yang terdata dalam laporan secara berkala, berdasarkan tahun ajaran; Tahap ketiga, pengolahan data mengadopsi teknik trianggulasi, dimana hasil wawancara mendalam disesuaikan dengan hasil observasi dan studi dokumen untuk memperoleh data dan informasi yang valid dan kredibel. Selanjutnya, laporan hasil penelitian ini dinarasikan berdasarkan gaya likung masing-masing pengelola jurnal untuk dipublikasikan.

\section{HASIL DAN PEMBAHASAN}

3.1 Prinsip Kerja COBIT 4.1 dan Sistem Informasi Akademik Universitas Halmahera

Sistem infomrasi akademik yang diadopsi oleh Perguruan Tinggi bertujuan untuk memudahkan pengelolaan administrasi perkuliahan yang melibatkan tenaga pendidik, tenaga kependidikan, dan mahasiswa. [15] berpendapat bahwa pengukuran keselarasan tujuan Teknologi Informasi dapat memberikan kontribusi terahdap kinerja Perguruan Tinggi, oleh sebab itu perlu diukur seberapa jauh keselarasan antara proses bisnis, aplikasi, dan strategi yang telah ditetapkan. Hal ini menunjukkan pentingnya audit sistem informasi menggunakan standar yang mumpuni. Dengan demikian, keranga kerja COBIT 4.1 dapat digunakan untuk mengukur tingkat kematangan berdasarkan domain Monitoring dan Evaluate (ME).

Kerangka kerja COBIT 4.1 telah digunakan oleh peneliti terdahulu dalam menganalisis efektivitas pembelajaran [16]. Meskipun demikian, ruang lingkup pembahasan tentang domain yang dievaluasi sangat kontekstual, tergantung permasalahan empiris yang menjadi tujuan pengukuran level kematangan dan nilai kesenjangan antara kondisi eksisting dan kondisi ideal [17]. Sebagaimana hasil penelitian [13] yang hanya fokus mengukur domain Delivery and Support (DS) di Perguruan Tinggi IBI Darmajaya. Hasil penelitian [18] yang fokus pada Domain Plan and Organize (PO) di Universitas Pembangunan Nasional "Veteran" Jawa 
Timur, serta hasil penelitian [19] yang fokus pada domain Delivery and Support (DS) di Universitas Sembilanbelas November Kolaka. Hal ini menunjukkan bahwa permasalahan empiris dalam implementasi Teknologi Informasi di Perguruan Tinggi memiliki perbedaan hambatan dan tantangan.

Tatakelola Teknologi Informasi mencakup kerangka kebijakan, prosedur dan kumpulan proses-proses yang bertujuan untuk mengarahkan dan mengendalikan sebuah lembaga agar dapat mencapai tujuan dengan nilai tambah, menguntungkan, serta memiliki resiko yang minim [20]. COBIT 4.1 merupakan standar kerangka kerja baku internasional yang digunakan untuk mengaudit tingkat kematangan tatakelola Teknologi Informasi [21]. Adapun, hasil analisis dari semua proses akan menunjukkan tingkat kematangan kondisi saat ini terhadap keseimbangan antara tujuan yang akan dicapai dari implementasi Teknologi Informasi terhadap kebijakan pihak penyelenggara [22]. Prinsip Kerangka kerja COBIT 4.1 dapat divisualisasikan sebagaimana Gambar 1 berikut.

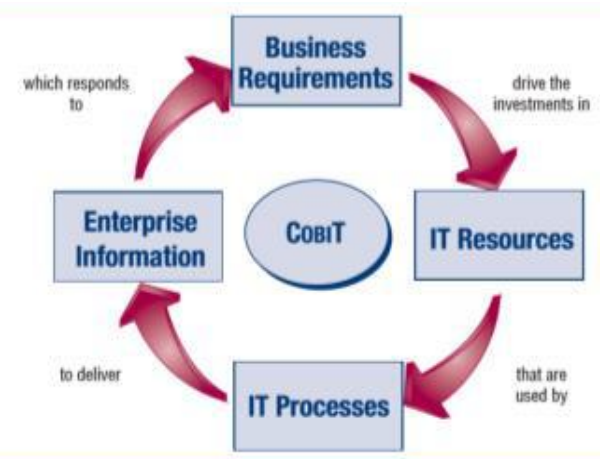

Gambar 1. Prinsip Kerja COBIT 4.1 [23]

Gambar 1 menunjukkan bahwa prinsip kerja COBIT 4.1 menekankan pada empat aspek yakni business requirement, IT resources, IT processes, enterprise information [23]. Suatu organisasi diharapkan mampu menerapkan tatakelola teknologi informasi dalam pencapaian tujuannya dengan mengintegrasikan cara optimal dari proses perencanaan dan pengorganisasian, pengimplementasian, dukungan serta proses pemantauan kinerja teknologi informasi [24]. Selanjutnya, [24] menunjukkan bahwa yang menjadi tolak ukur dalam standar COBIT 4.1 ialah maturity leve/yang digunakan untuk menentukan sampai mana tingkat proses dan pengelolaan IT ialah sebagai berikut : level O (0-0.49) Non-Exixtent, tidak memiliki proses pengawasan, prosedur untuk memantau efektivitas control internal, ada sedikit kesadaran akan kebutuhan eksternal yang memengaruhi IT, tidak memahami kekurangan atas proses pengaturan IT; Level 1 (0.50-1.49) Intial/Ad 


\section{Journal of Information Technology Ampera \\ Vol. 2, No. 2, August 2021 e-ISSN: 2774-2121}

https://journal-computing.org/index.php/journal-ita/index

Hoc, perusahaan mulai menyadari perlunya pengkajian terhadap suatu masalah namun tidak terdapat proses yang standar; Level 2 (1.50-2.49) Repeatable but Intuitive, prosedur diikuti tetapi masih ada tingkat ketergantungan yang tinggi pada pengetahuan individu. Tidak ada training atau komunikasi secara formal tentang prosedur standard an tanggung jawabnya jatuh pada individ. Ada ketergantungan yang tinggi pada individu dan sering terjadi eror; Level 3 (2.503.49) Defined Process, prosedur distrandarisasi tetapi tidak cukup canggih. Telah dilakukan training dan telah didokumentasikan, tetapi tetap dibutuhkan pelatihan; Level 4 (3.50-4.49) Managed and Measurable, terdapat kepatuhan sesuai dengan yang telah ditetapkan sebelumnya dan dapat mengetahui mengenai suatu masalah yang signifikan serta memberikan sebuah pelatihan dan kebutuhan sistem ditambahkan ke dalam aplikasi dan digunakan secara terpisah; Level 5 (4.50-5.00) Optimized, penyempitan proses ke tingkat praktek yang baik terjadi dan variasi terus berkurang. Terintegrasinya penggunaan IT dalam otomatisasi alur pekerjaan. Dalam meningkatkan kualitas IT dengan terdapatnya alat yang membantu meningkatkan efektif dan kualitas proses.

Dalam konteks penelitian ini, fokus utama pengukuran tingkat kematangan implementasi sistem informasi akademik di Universitas Halmahera terbatas pada domain Monitoring and Evaluate (ME). Berdasarkan hasil identifikasi dan analisis kinerja Sistem Informasi Akademik di Universitas Halmahera, dapat diklasifikasikan fungsi serta peran dari pengguna sistem (aktor) sebagaimana Tabel berikut.

Tabel 1. Klasifikasi Aktor dan Fungsi Sistem Informasi Akademik di Universitas Halmahera

\begin{tabular}{ll}
\hline \multicolumn{1}{c}{ Aktor } & \multicolumn{1}{c}{ Hak Akses } \\
\hline Administrator & Mengelola data dosen, data mahasiswa, data program studi, esrta \\
& memberikan hak akses terhadap user berdasrakan otoritas \\
& administrasi akademik. \\
\hline Mahasiswa & Mengakses informasi terkait dengan proses registrasi ulang, \\
& registrasi matakuliah, kartu studi, hasil studi, jadwal kuliah, transkrip \\
& nilai, tagihan kuliah, poin keaktifan, riwayat peminjaman buku, dan \\
& sebagainya. \\
\hline Dosen & Mengakses informasi terkait dengan jadwal kuliah, evaluasi \\
& pembelajaran, serta mengelola data mahasiswa sesuai dengan \\
& jadwal akademik.
\end{tabular}

Sumber : Hasil Identifikasi Proses Bisnis Sisformik Universitas Halmahera, 2019.

Tabel 1 merupakan klasifikasi aktor dan fungsi sistem informasi akademik di Universitas Halmahera, yang perlu dikendalikan dan dievaluasi menggunakan kerangka COBIT 4.1 berdasarkan domain Monitoring and Evaluate (ME) berdasarkan tingkat kematangan pada masing-masing indikator sebagai berikut : 
Monitor and Evaluate IT Performance (ME1). Monitor and Evaluate Internal Control (ME2), Obtain Independent Assurance (ME3), dan Provide IT Governance (ME4). Dengan demikian dapat direkomendasikan strategi untuk mengatasi kesenjangan antara kondisi eksiting dengan kondisi ideal.

Universitas Halmahera mengguakan SISFORMIK untuk proses pendukung perkulihan yang meliputi proses aktor SISFORMIK adalah: Admin dapat mengakses: data dosen, data mahasiswa, data program studi, password dosen, password mahasiswa, referensi, dan pengaturan registrasi. Mahasiswa dapat mengakses: rencana studi, hasil studi, transkip nilai, registrasi, ubah password dan mahasiswa juga dapat mencetak KRS, KST, transkip nilai serta dapat melihat informasi pembayaran, perkembangan IPK dan KST presemester, informasi akademi, dan informasi mahasiswa. Dosen dapat mengakses pengimputan nilai. Kaprogdi dapat mengakses data mahasiswa meliputi: daftar mahasiswa, aktif genap, dan tidak aktif genap. Selanjutnya, data akademi meliputi: matakuliahan, kelas yang ditawakan, dosen, nilai, nilai hasil studi lalu, dan presensi. Selain itu, data pendukung meliputi: pilah (rumpunmatakuliahan), nilai dan bobot, status mahasiswa, jam awal, jam akhir, dan semerter. Maupun, laporan meliputi: cetak berkas, resensi, presensi kuliah, presensi UTS, dan presensi UAS.

3.2 Hasil Monitoring dan Evaluasi, Ringkasan Identifikasi Masalah dan Rekomendasi dan Tingkat Kematangan

Berdasarkan hasil pengolahan data dapat diketahui ringkasan masalah sera rekomendasi untuk mengoptimalkan Monitoring and Evaluate IT Performance (ME1), sebagai beriku : masih diperlukan suatau adaptasi terhadap proses penggunaan sistem informasi; masih kurangnya pemantauan terhadap pengumpulan data yang akurat dan tepat waktu; belum adanya prosedur penanganan penyebab kesalahan yang terjadi pada sistem; belum adanya umpan balik terhadap tinjauan manajemen terkait sejauh mana tujuan yang telah tercapai maupun terget kinerja yang sudah terpenuhi. Berdasarkan masalah-masalah yang telah diidentifikasi, hasil penilaian Monitoring and Evaluate IT Performance (ME1) dapat dilihat pada Tabel 1 berikut.

Tabel 1. Hasil Perhitungan Nilai Evaluasi Monitoring and Evaluate IT Performance (ME1)

\begin{tabular}{|l|l|c|c|}
\hline \multicolumn{1}{|c|}{ Domain } & $\begin{array}{c}\text { Rata-Rata } \\
\text { Hasil }\end{array}$ & Keterangan \\
\hline ME1.1.1 & Monitoring Approach & 3,8 & $\begin{array}{c}\text { Managed and } \\
\text { Measurable }\end{array}$ \\
\hline ME1.1.2 & Monitoring Approach & 3 & Defined Process \\
\hline
\end{tabular}




\section{Journal of Information Technology Ampera}

Vol. 2, No. 2, August 2021 e-ISSN: 2774-2121

https://journal-computing.org/index.php/journal-ita/index

\begin{tabular}{|l|l|c|c|}
\hline ME1.2.3 & $\begin{array}{l}\text { Definition and Collection or } \\
\text { Monitoring Data }\end{array}$ & 4 & $\begin{array}{c}\text { Managed and } \\
\text { Measurable }\end{array}$ \\
\hline ME1.3.1 & Monitoring Method & 3 & Defined Process \\
\hline ME1.4.1 & Performance Assessment & 4,5 & Optimized \\
\hline ME1.5.1 & Board and Executive Reporting & 3 & $\begin{array}{c}\text { Defined Process } \\
\text { Managed and } \\
\text { Measurable }\end{array}$ \\
\hline ME1.5.2 & Board and Executive Reporting & 4 & $\begin{array}{c}\text { Defined Process } \\
\text { Managed and } \\
\text { Measurable }\end{array}$ \\
\hline ME1.5.3 & Board and Executive Reporting & 3 & \begin{tabular}{c} 
Managed and \\
Measurable \\
\hline ME1.6.1
\end{tabular} \\
\hline ME1.6.2 & Remedial Actions & 3,8 & $\begin{array}{c}\text { Maged and } \\
\text { Measurable }\end{array}$ \\
\hline
\end{tabular}

Tabel 1 menunjukkan hasil penilaian terhadap domain Monitoring and Evaluate IT Performance (ME1). Mempertimbangkan hal tersebut, rekomendasi untuk mengatasi masalah-masalah yang berhubungan dengan Monitoring and Evaluate IT Performance (ME1) ialah sebagai berikut : perlunya sosialisasi untuk adaptasi terhadap proses penggunaan teknologi agar mahasiswa dapat paham dan mengerti sistem yang di gunakan; diperlukan adanya monitor terhadap kerangka pemantauan agar dapat menerapkan solusi bisnis terkait teknologi informasi; diharapkan dibentuk suatu proses dalam sistem untuk melacak akar penyebab kesalahan yang terjadi pada SISFORMIK agar lebih optimal; dilakukan umpan balik terhadap laporan tinjauan manajemen yang terpantau agar tujuan bisnis dan target kinerja dapat terpenihi; Perlunya pemantauan terhadap proses pengumpulan data yang akurat dan tepat waktu secara berkala.

Selanjutnya, masalah yang diidentifikasi berkaitan dengan Monitoring and Evaluate Internal Control (ME2) ialah sebagai berikut : belum dipantaunya pelaporan masalah kepada bagian ITC yang bertanggung jawab secara kolektif; kurangnya pemantauan terhadap efisiensi dan efektivitas kontrol teknologi informasi untuk managerial internal; diperlukan analisis dan identifikasi yang mendalam terhadap penyebab kesalahan kontrol pada sistem. Berdasarkan masalah-masalah yang telah diidentifikasi, hasil penilaian Monitoring and Evaluate Internal Control (ME2) dapat dilihat pada Tabel 2 berikut.

Tabel 2. Hasil Perhitungan Nilai Evaluasi Monitoring and Evaluate Internal Control (ME2)

\begin{tabular}{|c|c|c|c|}
\hline Domain & \multicolumn{1}{|c|}{ Keterangan } & Rata-Rata Hasil & Keterangan \\
\hline ME2.1.1 & $\begin{array}{l}\text { Monitoring of internal control } \\
\text { framework }\end{array}$ & 4,1 & $\begin{array}{c}\text { Managed and } \\
\text { Measurable }\end{array}$ \\
\hline
\end{tabular}


Journal of Information Technology Ampera

Vol. 2, No. 2, August 2021 e-ISSN: 2774-2121

https://journal-computing.org/index.php/journal-ita/index

\begin{tabular}{|c|l|c|c|}
\hline ME2.2.1 & Supervisory review & 4 & $\begin{array}{c}\text { Managed and } \\
\text { Measurable }\end{array}$ \\
\hline ME2.3.1 & Control exceptions & 3,8 & $\begin{array}{c}\text { Managed and } \\
\text { Measurable }\end{array}$ \\
\hline ME2.3.2 & Control exceptions & 3,9 & $\begin{array}{c}\text { Managed and } \\
\text { Measurable }\end{array}$ \\
\hline ME2.4.1 & Control self-assessment & 3,5 & $\begin{array}{c}\text { Managed and } \\
\text { Measurable }\end{array}$ \\
\hline \multicolumn{2}{|c|}{ Rata-Rata } & 3,86 & $\begin{array}{c}\text { Managed and } \\
\text { Measurable }\end{array}$ \\
\hline
\end{tabular}

Tabel 2 menunjukkan hasil penilaian tterhadap domain Monitoring and Evaluate Internal Control (ME2). Mempertimbangkan hal tersebut, rekomendasi untuk mengatasi masalah yang berhubungan dengan Monitoring and Evaluate Internal Control (ME2) ialah sebagai berikut: Dilakukan pemantauan terhadap kontrol teknologi informasi berdasarkan efisiensi dan efektivitas umtuk manajerial internal; Melakukan analisa kesalahan pada sistem supaya dapat ditemukan solusi dari penyebabnya; Dibentuknya kerangka pemantauan untuk evaluasi kelengkapan dan efektivitas pengendalian manajemen atas proses teknologi informasi.

Masalah yang telah diidentifikasi berhubungan dengan Monitoring and Evaluate Internal Control Obtain Independent Assurance (ME3) ialah sebagai berikut : perlunya pemantauan terhadap kepatuhan kebijakan teknologi informasi, standar prosedur, dan metodologi dengan persyaratan hukum dan peraturan berlaku; Kurangnya pemantauan terhadap kebijakan peraturan serta persyaratan eksternal dalam IT; kurangnya sosialisasi peraturan terhadap kebijakan teknologi informasi yang diterapkan. Berdasarkan masalah-masalah yang telah diidentifikasi, hasil penilaian Monitoring and Evaluate Internal Control Obtain Independent Assurance (ME3) dapat dilihat pada Tabel 3 berikut.

Tabel 3. Hasil Perhitungan Nilai Evaluasi Monitoring and Evaluate Internal Control Obtain Independent Assurance (ME3)

\begin{tabular}{|c|l|c|c|}
\hline Domain & \multicolumn{1}{|c|}{ Keterangan } & $\begin{array}{c}\text { Rata-Rata } \\
\text { Hasil }\end{array}$ & Keterangan \\
\hline ME3.1.1 & $\begin{array}{l}\text { Identification of External Legal, Regulatory } \\
\text { and Contractual Compliance Requirements }\end{array}$ & 3,5 & $\begin{array}{c}\text { Managed and } \\
\text { Measurable }\end{array}$ \\
\hline ME3.2.1 & $\begin{array}{l}\text { Optimization of Response to External } \\
\text { Requirements }\end{array}$ & 3,9 & $\begin{array}{c}\text { Managed and } \\
\text { Measurable }\end{array}$ \\
\hline ME3.3.1 & $\begin{array}{l}\text { Evaluation of Compliance With External } \\
\text { Requirements }\end{array}$ & 4 & $\begin{array}{c}\text { Managed and } \\
\text { Measurable }\end{array}$ \\
\hline ME3.4.1 & Positive Assurance of Compliance & 4 & $\begin{array}{c}\text { Managed and } \\
\text { Measurable }\end{array}$ \\
\hline ME3.5.1 & Integrated Reporting & 3 & Defined Process \\
\hline
\end{tabular}




\section{Journal of Information Technology Ampera}

Vol. 2, No. 2, August 2021 e-ISSN: 2774-2121

https://journal-computing.org/index.php/journal-ita/index

\begin{tabular}{|c|c|c|}
\hline Rata-Rata & 3,68 & $\begin{array}{c}\text { Managed and } \\
\text { Measurable }\end{array}$ \\
\hline
\end{tabular}

Tabel 3 menunjukkan hasil penilaian terhadap domain Monitoring and Evaluate Internal Control Obtain Independent Assurance (ME3). Mempertimbangkan hal tersebut, rekomendasi untuk menyelesaikan masalah yang berhubungan dengan aspek Monitoring and Evaluate Internal Control Obtain Independent Assurance (ME3) ialah sebagai berikut : perlunya agenda pemantauan secara berkala terhadap kebijakan dan peraturan dalam IT agar berjalan sesuai dengan kebijakan instansi; diadakannya sosialisasi terkait penyusuaian kontrak dan peraturan terhadapa kebijakan sistem; diharapkan adanya pemantauan terhadap teknologi informasi agar terealisasi secara teratur mengingat persyaratan dan perturan dapat berubah mengikuti kebijakan-kebijakan baru.

Masalah-masalah yang telah teridentifikasi berhubungan dengan domain Monitoring and Evaluate Provide IT Governance (ME4) ialah sebagai berikut : masih kurangnya pengawasan terhadap kerangka tata kelola teknologi informasi; masih kurangnya penerapan aturan dan sistem kerja teknologi untuk mendukung tujuan bisnis; belum adanya monitoring untuk pengelolaan aset teknologi informasi instansi; masih kurangnya pemahaman antara bisnis dan teknologi informasi untuk tujuan strategi bisnis instansi. Berdasarkan masalah-masalah yang telah diidentifikasi, hasil penilaian Monitoring and Evaluate Provide IT Governance (ME4) dapat dilihat pada Tabel 4 berikut.

Tabel 4. Hasil Perhitungan Nilai Evaluasi Monitoring and Evaluate Provide IT Governance (ME4)

\begin{tabular}{|c|l|c|c|}
\hline Domain & \multicolumn{1}{|c|}{ Keterangan } & $\begin{array}{c}\text { Rata-Rata } \\
\text { Hasil }\end{array}$ & Keterangan \\
\hline ME4.1.1 & $\begin{array}{l}\text { Establishment of an IT Governance } \\
\text { Framwork }\end{array}$ & 4,2 & $\begin{array}{c}\text { Managed and } \\
\text { Measurable }\end{array}$ \\
\hline ME4.1.2 & $\begin{array}{l}\text { Establishment of an IT Governance } \\
\text { Framwork }\end{array}$ & 4 & $\begin{array}{c}\text { Managed and } \\
\text { Measurable }\end{array}$ \\
\hline ME4.2.1 & Strategic Alignment & 3,5 & $\begin{array}{c}\text { Managed and } \\
\text { Measurable }\end{array}$ \\
\hline ME4.2.2 & Strategic Alignment & 4 & $\begin{array}{c}\text { Managed and } \\
\text { Measurable }\end{array}$ \\
\hline ME4.2.3 & Strategic Alignment & 4,2 & $\begin{array}{c}\text { Managed and } \\
\text { Measurable }\end{array}$ \\
\hline ME4.2.4 & Strategic Alignment & 4,3 & $\begin{array}{c}\text { Managed and } \\
\text { Measurable }\end{array}$ \\
\hline ME4.3.1 & Value Delivery & 3 & $\begin{array}{c}\text { Defined Process } \\
\text { Managed and } \\
\text { Measurable }\end{array}$ \\
\hline ME4.3.2 & Value Delivery & 3,9 & \\
\hline
\end{tabular}

72 | Monitoring dan Evaluasi Sistem Informasi Akademik Universitas ..... 


\begin{tabular}{|c|c|c|c|}
\hline ME4.3.3 & Value Delivery & 4 & $\begin{array}{c}\text { Managed and } \\
\text { Measurable }\end{array}$ \\
\hline ME4.4.1 & Resource Management & 4,1 & $\begin{array}{c}\text { Managed and } \\
\text { Measurable }\end{array}$ \\
\hline Rata-Rata & 3,92 & $\begin{array}{c}\text { Managed and } \\
\text { Measurable }\end{array}$ \\
\hline
\end{tabular}

Tabel 4 menunjukkan hasil penilaian terhadap domain Monitoring and Evaluate Provide IT Governance (ME4). Mempertimbangkan hal tersebut, rekomendasi untuk mengatasi masalah yang berhubungan dengan domain Monitoring and Evaluate Provide IT Governance (ME4) ialah sebagai berikut : Perlunya pengawasan untuk penyelarasan kerangka tata kelola teknologi informasi dengan kepatuhan hukum terhadap peraturan, strategi dan tujuan instansi; Diharapkan karyawan benar-benar paham mengenai tujuan antara bisnis dan teknologi informasi sebagai salah satu tujuan bisnis instansi; Dipantaunya penerapan penggunaan sistem yang baik terhadap aturan penggunaan sistem dari E-presensi demi mendukung tujuan strategi bisnis instansi; Perlunya analisis dan monitoring pengelolaan dalam aset teknologi informasi instansi; Pengawasan berkala terhadap alokasi dan penilaian sumber daya teknologi informasi sesuai dengan tujuan strategi institusi.

Berdasarkan hasil analisis berdasarkan masalah yang berhubungan dengan Monitoring and Evaluate (ME) pada Sistem Informasi Akademik Universitas Halmahera, dapat diketahui tingkat kematangan pada domain Monitoring and Evaluate (ME) sebagaimana Tabel berikut.

Tabel 5. Hasil Pertihungan Maturirty Level Monitoring and Evaluate (ME)

\begin{tabular}{|c|c|c|c|}
\hline Sub Domain & Keterangan & Nilai & Kondisi \\
\hline ME1 & $\begin{array}{c}\text { Monitor and Evaluate IT } \\
\text { Performance }\end{array}$ & 3,59 & $\begin{array}{c}\text { Defined } \\
\text { Process }\end{array}$ \\
\hline ME2 & $\begin{array}{c}\text { Monitor and Evaluate Internal } \\
\text { Control }\end{array}$ & 3,86 & $\begin{array}{c}\text { Defined } \\
\text { Process }\end{array}$ \\
\hline ME3 & Obtain Independent Assurance & 3,68 & $\begin{array}{c}\text { Defined } \\
\text { Process }\end{array}$ \\
\hline ME4 & Provide /T Governance & 3,92 & $\begin{array}{c}\text { Defined } \\
\text { Process }\end{array}$ \\
\hline \multicolumn{2}{|c|}{ Rata - Rata } & 3,8 & $\begin{array}{c}\text { Defined } \\
\text { Process }\end{array}$ \\
\hline
\end{tabular}

Tabel 5 merupakan hasil perthitungan tingkat kematangan pada domain Monitoring and Evaluate (ME) yang menunjukkan bahwa rata - rata nilai Maturity Level pada domain ME yaitu 3,8 dimana sudah ada di level Defined Process. 


\section{Journal of Information Technology Ampera \\ Vol. 2, No. 2, August 2021 e-ISSN: 2774-2121}

https://journal-computing.org/index.php/journal-ita/index

Sementara itu, nilai kesenjangan antara kondisi eksisting dengan nilai ekspektasi dapat dilihat pada Tabel 6 berikut.

Tabel 6. Kesenjangan antara Kondisi Eksisting dan Ekspektasi

\begin{tabular}{|c|c|c|c|}
\hline \multirow{2}{*}{ Domain } & \multicolumn{3}{|c|}{ Nilai Maturity Level Rata - Rata Keseluruhan } \\
\cline { 2 - 4 } & Saat Ini & Diharapkan & GAP \\
\hline ME & 3,8 & 4 & $4-3,8$ \\
\hline \multicolumn{3}{|c|}{ Rata - Rata } & 0,24 \\
\hline
\end{tabular}

Tabel 6 menunjukkan bahwa nilai kondisi eksisting ialah 3.8 sedangkan nilai yang diharapkan ialah 4. Hal ini menunjukkan adanya kesenjangan 0,24 dari kondisi eksiting ke nilai yang diharapkan. Beberapa kendala yang dihadapi oleh pengelola sistem informasi akademik di Universitas Halmahera ialah pengambilan matakuliajh yang masih acak dan belum terstruktutr, jadwal registrasi yang belum tentu, tidak bisa mencetak referensi, pembayaran uang kuliah yang belum terintegrasi, dan error atau bug yang sering ditemukan pengguna ketika mengakses Sistem Informasi Akademik Universitas Halmahera.

\section{KESIMPULN}

Berdasarkan hasil monitoring dan evaluasi sistem informasi akademik Universitas Halmahera menggunakan kerangka kerja COBIT 4.1 dapat disimpulkan bahwa Universitas Halmahera telah mengimplementasikan sistem informasi akademik dengan status defined process, dimana tingkat kematangan bernilai 3,8 dengan nilai kesenjangan sebesar 0.24. Selanjutnya, berdasarkan hasil perhitungan tingkat kematangan pada subdomain (ME1-ME4), dapat diketahui tingkat kematangan dengan nilai tertinggi ialah 3.92 pada ME4. Sedangkan, tingkat kematangan dengan nilai terendah ialah 3.59 pada ME1.

\section{DAFTAR PUSTAKA}

[1] A. S. Barkah and M. Dianingrum, "Evaluasai Penerapan Sistem Informasi dan Teknologi Informasi Menggunakan Cobit Framework di STMIK AMIKOM Purwokerto," J. Probisnis, vol. 8, no. 1, pp. 22-30, 2015.

[2] F. Sonata, "Strategi Penguatan Audit Tata Kelola dan Manajemen Risiko Teknologi Informasi pada Usaha Startup Menggunakan Control Objective for Information and Related Technology Framework (Studi Kasus : Otoritas Jasa Keuangan)," J. Komunikasi, Media dan Inform., vol. 7, no. 1, pp. 3036, 2018.

[3] M. Purba, "Perancangan Model Tata Kelola Teknologi Informasi Berbasis 
Cobit pada Proses Mengelola Sumber Daya Manusia IT Pada Politeknik ANIKA," J. TIPS, vol. 9, no. 2, pp. 46-53, 2019.

[4] M. Chandra, A. I. Suroso, and I. Hermadi, "Evaluasi Cobit dan Perancangan IT Balanced Scorecard untuk Perbaikan Penerapan System Development," J. Manaj. Teknol., vol. 14, no. 3, pp. 231-245, 2015.

[5] Haviluddin, H. J. Setyadi, P. P. Widagdo, and M. Taruk, "Perbandingan Fasilitas COBIT 4.0/4.1 dan COBIT 5 Frameworks: Studi Pengguna Berdasarkan Literatur," in Prosiding Seminar IImu Komputer dan Teknologi Informasi, 2016, vol. 1, no. 1, pp. 30-37.

[6] T. Sunarsa, "The Maturity Level of IT Governance Based On Cobit Framework 4.0 on DS and ME Domains at PT . Milano Mitra Abadi," J. Tech-E, vol. 2, no. 1, pp. 24-29, 2018.

[7] A. K. Darmawan and A. Dwiharto, "Pengukuran Capability Level Kualitas Layanan E-Government Kabupaten Pamekasan Menggunakan Fremework COBIT 5," INTENSIF, vol. 3, no. 2, pp. 93-103, 2019.

[8] I. G. L. A. Raditya and I. W. D. P. Adnyana, "Evaluasi Tatakelola Sistem Informasi Akademik STIMIK Primakara Menggunakan Framework COBIT 5," J. Teknol. Inf. dan Komput., vol. 5, no. 1, pp. 40-49, 2019.

[9] J. Soejanto, Suprapto, and A. R. Perdanakusuma, "Evaluasi Tata Kelola Teknologi Informasi pada PT. Aerofood Indonesia Bandar Udara Soekarno Hatta Cengkareng dengan Menggunakan Framework COBIT 5," J. Pengemb. Teknol. Inf. dan IImu Komput., vol. 2, no. 11, pp. 4714-4721, 2018.

[10] M. P. Darenoh, A. D. Manuputty, and F. Surachman, "Evaluasi Tingkat Kapabilitas Kinerja Layanan TI pada Layanan Internet Bidang A Menggunakan Framework COBIT 5 Domain MEA 01 (Studi Kasus: Satuan Organisasi XYZ - Lembaga ABC)," J. Tek. Inform. dan Sist. Inf., vol. 4, no. 8, pp. 58-66, 2018.

[11] K. Marzuki, Apriani, and Z. L. A. Mardedi, "Evaluasi Penerapan Teknologi Informasi E-Learning pada Kampus Swasta Menggunakan COBIT 4.1 (Studi Kasus : Program Studi Ilmu Kompter, Universitas Bumigora)," B/Te, vol. 1, no. 2, pp. 161-166, 2019.

[12] N. Arviana, Suprapto, and Y. T. Mursityo, "Evaluasi Tingkat Kematangan Tata Kelola Teknologi Informasi pada Politeknik Kesehatan Kemenkes Surabaya Menggunakan Kerangka Kerja COBIT 4.1 dengan Domain DS (Deliver and Support) dan ME (Monitor and Evaluate)," J. Pengemb. Teknol. Inf. dan Ilmu Komput, vol. 3, no. 4, pp. 3157-3165, 2019.

[13] Amnah, "Audit Sistem Informasi Layanan di Biro Administrasi Akademik pada Institut Informatika \& Bisnis Darmajaya Menggunakan COBIT 4.1," in Konferensi Nasional Sistem \& Informatika, 2015, pp. 9-10.

[14] R. Hadiyanto et al., "Audit Sistem Informasi Akademik Menggunakan 


\section{Journal of Information Technology Ampera \\ Vol. 2, No. 2, August 2021 e-ISSN: 2774-2121}

https://journal-computing.org/index.php/journal-ita/index

Framework COBIT 4.1 (Studi Kasus Universitas ARS Bandung)," J. Inform. Polinema, vol. 6, no. 3, pp. 55-64, 2020.

[15] Setyowati and S. Harjanto, "Audit Sistem Informasi pada Sistem Informasi Akademik Perspektif Proses Bisnis Internal Balanced Scorecared dan Standar Cobit 4.1 (Studi Kasus: STMIK SINAR NUSANTARA SURAKARTA)," J. IIm. SINUS, vol. 13, no. 1, pp. 13-20, 2015.

[16] S. Hanief, "Pengukuran Efektivitas Pembelajaran Jarak Jauh Menggunakan Framework COBIT 4.1 dengan Pola Sinkronus," in Konferensi Nasional Sistem dan Informatika, 2015, pp. 9-10.

[17] M. Ashari, "Audit Information Technology (IT) Governance Pada Sekolah Tinggi Manajemen Informatika Dan Komputer (STMIK) Lombok Menggunakan Framework COBIT 4.1," J. Bianglala Inform., vol. 3, no. 2, pp. 1-9, 2015.

[18] M. Idhom, Irwansyah, and R. Alit, "Analisis Sumber Daya Manusia Teknologi Informasi Menggunakan Kerangka Kerja COBIT 4.1 (Studi Kasus: Unit Pelaksana Teknis Telematika Universitas Pembangunan Nasional 'Veteran ' Jawa Timur)," KINETIK, vol. 1, no. 2, pp. 101-106, 2016.

[19] A. A. Hamsyani, "Evaluasi Maturity Level dalam Tatakelola Teknologi Informasi Universitas Sembilan Belas November Kolaka Menggunakan Framework Cobit 4.1," Indones. J. Netw. Secur., vol. 5, no. 2, pp. 42-48, 2016.

[20] Wisda, "Pengukuran Tingkat Kematangan IT Governance Pada Layanan Akademik STMIK AKBA Dengan Framework Cobit 4.1 ( Studi Kasus: STMIK AKBA Makassar )," J. Speed, vol. 8, no. 1, pp. 14-21, 2016.

[21] W. Bagye, "Analisis Tingkat Kematangan Sistem Informasi Akademik Menggunakan Framework COBIT 4.1 (Studi Kasus: STMIK Lombok)," J. Speed, vol. 8, no. 1, pp. 1-7, 2016.

[22] R. Alit, I. D. Pratiwi, and M. Idhom, "Tingkat Kematangan Infrastruktur Teknologi Informasi pada Domain Acquire and Implement Menggunakan COBIT 4.1 (Studi Kasus: UPT Perpustakaan Universitas Pembangunan Nasional 'Veteran' Jawa Timur)," KINETIK, vol. 2, no. 3, pp. 227-234, 2017.

[23] R. H. Puspitoputra, Y. T. Mursityo, and A. D. Herlambang, "Pengukuran Tingkat Kematangan Tata Kelola Teknologi Informasi Berdasarkan Framework COBIT 4.1 Proses Acquire and Implement (Al) pada PT. Samudra Sarana Logistik," J. Pengemb. Teknol. Inf. dan IImu Komput., vol. 4, no. 1, pp. 158-165, 2020.

[24] A. Rubhasy and D. M. Milasari, "Audit Tingkat Kematangan Proses Internal Key Logistics System Menggunakan Kerangka Kerja Cobit 4.1 Pada Perusahaan Ekspedisi XYZ," PETIR, vol. 13, no. 1, pp. 101-109, 2020. 